\title{
Blood Pressure in Healthy Youngsters is modified by Vitamin-D Supplementation
}

\author{
Rune Tønnesen ${ }^{1}$, Kristian Buch ${ }^{2}$, Peter Hambak Hovind ${ }^{3}$, Lars Thorbjørn Jensen ${ }^{1,4}$ and Peter Schwarz ${ }^{2,4 *}$ \\ ${ }^{1}$ Department of Clinical Physiology and Nuclear Medicine, Herlev Gentofte University Hospital, Copenhagen, Denmark \\ ${ }^{2}$ Department of Endocrinology, Diabetes and Bone-metabolic Research Unit, Rigshospitalet, Copenhagen, Denmark. \\ ${ }^{3}$ Department of Clinical Physiology and Nuclear Medicine, Rigshospitalet, Copenhagen, Denmark \\ ${ }^{4}$ Faculty of Health Sciences, University of Copenhagen, Denmark
}

${ }^{*}$ Corresponding author: Peter Schwarz, MD, DMSci., Professor, Department of Endocrinology, Rigshospitalet, Copenhagen, Blegdamsvej 9, 2100 København, Denmark; Office: 3545 7574; Phone: 5239 4595; E-mail: peter.schwarz@regionh.dk

Received: February 14, 2019; Accepted: February 22, 2019; Published: March 12, 2019;

\begin{abstract}
Objective

Our study aimed to investigate the effect of vitamin D supplementation on blood pressure in vitamin D insufficient young volunteers compared to an age matched control group with sufficient levels of vitamin D. Secondarily we aimed to evaluate the effect of vitamin D supplementation on the RAAS and sympathetic nervous system.
\end{abstract}

\section{Design}

Single centre, Randomised controlled Trial.

\section{Methods}

Fifteen vitamin D insufficient and 15 vitamin D sufficient youngsters (18-25 years) were recruited for a clinically controlled trial of 6 months vitamin D supplementation ( $30 \mu \mathrm{g} /$ day). At baseline, 30 days, 90 days and 180 days, $24 \mathrm{~h}$ systolic and diastolic blood pressure, and 25-hydroxyvitamin D, angiotensinogen, renin, angiotensin (I+II), aldosterone, and catecholamines were measured.

\section{Results}

The difference between baseline visit and 180 days visit for the vitamin D insufficiency group compared to the control group was; systolic BP (daytime) decreased -6.6 (Interquartile Range 2.4) $\mathrm{mmHg}(\mathrm{p}=0.009)$, diastolic BP (daytime) decreased $-4.5(2.1) \mathrm{mmHg}(\mathrm{p}=0.03)$, norepinephrine decreased -0.80 $(0.21) \mathrm{nmol} / \mathrm{L},(\mathrm{p}=0.0002)$. There was no effect of vitamin D supplementation on night time systolic or diastolic BP, and no effect on angiotensinogen, renin, angiotensin (I+II), aldosterone or epinephrine.

\section{Conclusion}

We observed that 180 days of vitamin D supplementation in normal youngsters with insufficient vitamin D significantly lowered systolic and diastolic BP during daytime. Vitamin D supplementation also significantly lowered circulating norepinephrine. Nothing happened in the control group with normal vitamin D. Hence, it is tempting to conclude that vitamin D acts on BP through SNS as no changes were observed in the RAAS.

Keywords: Vitamin D, Blood pressure, Catecholamines, Normal Youngsters, RAAS.

\section{Introduction}

Vitamin D and its importance for skeletal development is well known. The research field of Vitamin D has been broadend even to gene regulation on a grand scale [1]. Recently, Vitamin D deficiency has been found associated with hypertension and several other diseases in epidemiological studies [2,3] and is a risk factor for cardiovascular mortality [4] and cardiovascular incidents $[5,6]$ Vitamin D deficiency is prevalent in all ages [7], races [8], geographical regions [9], socioeconomic strata and seasons [10]. Hypertension and vitamin $\mathrm{D}$ deficiency are both prevalent worldwide $[9,11,12]$ and a causative link between these may potentially have wide public health implications. Hypertension and heart disease are an enormous burden for society. The total direct and indirect costs in 2010 were estimated to $\$ 273$ billion and $\$ 172$ billion respectively in the US [13]. Vitamin D supplementation could potentially be a novel pathway to ease the burden of hypertension, given the low cost and mild adverse effects $[14,15]$. Intervention studies with vitamin D supplementation for treatment of hypertension have yielded inconsistent results [16-34]. This inconsistency could be attributed to factors with influence on 
S-25[OH]D or attenuate the outcome blood pressure e.g. seasonal variation $[20,30]$, non-cardiovascular comorbidity [16-18, 20-24, $26,27,30-32,34]$, medication $[16-18,21-28,30-32,34]$ and normal physiological $(\mathrm{S}-25[\mathrm{OH}] \mathrm{D}>50 \mathrm{nmol} / \mathrm{L})$ vitamin $\mathrm{D}$ levels $[16-18,21$, $24,26-28,30,32,34]$ before treatment.

Regulation of Blood Pressure (BP) acts mainly through the Renin-Angiotensin-Aldosterone System (RAAS) and the Sympathetic Nervous System (SNS) [35]. Vitamin D supplementation is associated with the cardiac autonomic tone in healthy humans [36], and could indicate a modulating role of vitamin D in the SNS.

Vitamin D is a secosteroid hormone although it can be obtained through food intake [37]. The main source of vitamin D is represented by its synthesis in the body itself [38]. Vitamin D in its active form, 1 , 25-dihydroxyvitamin $\mathrm{D}_{3}\left[1,25(\mathrm{OH})_{2} \mathrm{D}_{3}\right]$, crosses the cell membrane, enters the target cell and binds to a specific nuclear vitamin $\mathrm{D}$ receptor. The receptor is found in the kidneys, and in mice a decrease in vitamin D is found to increase renin [39]. Vitamin D supplementation could potentially lower renin, which is the first step in the RAAS-pathway and might have a cascading effect on the RAAS-pathway resulting in lowering angiotensin and aldosterone with a lower systemic BP as a result. In rats, vitamin $\mathrm{D}$ depletion leads to increases in norepinephrine [40] and increases in systolic BP [41].

To take into account the factors that could blunt or attenuate the effect of vitamin $\mathrm{D}$ on $\mathrm{BP}$ regulation an investigative setting; with healthy young adults and a group with constant vitamin D concentration acting as control group would be preferable to deal with the seasonal variation. In such a setting, it would be possible to get a more clear view of the effects of vitamin D on BP regulation. To our knowledge, this has not yet been done.

Our clinical trial aimed to investigate the effect of vitamin D supplementation on the BP in two groups; one with vitamin D insufficiency and one with normal levels of vitamin D. The secondary aim was to investigate the effects of vitamin D supplementation on RAAS and the autonomous nervous system, hopefully elucidating possible underlying mechanisms.

\section{Methods}

\section{Study Design and Participants}

The study was carried out from October 2012 to August 2014 as a single center, parallel-group, clinical controlled trial conducted at the Department of Clinical Physiology, Nuclear Medicine \& PET, Rigshospitalet, Copenhagen, Denmark.

Subjects were recruited from a screening of 99 young adults aged 18-25 years. We found 27 potential controls with sufficient vitamin D levels $(\mathrm{S}-25[\mathrm{OH}] \mathrm{D}>80 \mathrm{nmol} / \mathrm{L})$ and 33 with insufficient vitamin D levels $(\mathrm{S}-25[\mathrm{OH}] \mathrm{D}<50 \mathrm{nmol} / \mathrm{L})$ and all were invited to participate by e-mail. Participants were excluded if they suffered from diseases or took medication known to interfere with vitamin $\mathrm{D}$ as well as pregnancy, hypertension, heart- or kidney disease, diabetes, epilepsy, bone diseases, use of anabolic or systemic steroids

After 15 controls and 15 vitamin D insufficient volunteers accepted the invitation further enrollment was stopped. After enrolment serum $25[\mathrm{OH}] \mathrm{D}$ was remeasured to assure that each participant was within inclusion limits of each group on the first day of the study. Each subject's respective vitamin D level was a result of their lifestyle and genes as all participants were vitamin D so-called naive as only subjects who did not take supplementation was included in the study.

\section{Ethics}

We performed the study in accordance to the Helsinki II declaration considering biomedical research. Informed, written consent was obtained from all participants prior to enrollment. The Ethical Committee of the Capital Region, Denmark (ref. no. H-12012-023) approved the project.

\section{Intervention}

The vitamin D insufficiency group was supplemented to increase the concentration of S-25[OH]D and the control group were supplemented to be kept at S-25[OH]D normal steady state concentration $>80 \mathrm{nmol} / \mathrm{L}$. All participants were supplemented by 30 $\mu \mathrm{g}$ cholecalciferol and $1.200 \mathrm{mg}$ of calcium per day. The participants were instructed to bring all supplied containers and remaining tablets to next visit for compliance estimation.

\section{Study Program}

The program comprised four visits, at baseline, after one month, three months, and six months. All visits took place between 08.00 and 17.00; participants had fasted for two hours prior to all visits.

Participants rested $30 \mathrm{~min}$ supine position before blood sampling for the assessment of S-25[OH]D, angiotensinogen, renin activity, angiotensin I, angiotensin II, aldosterone, epinephrine, and norepinephrine. Office BP in sitting position was measured and 24-hour ambulatory BP (24hr-AMBP) recording was performed. Vitamin D supplementation needed until next visit was handed to the participants in containers of 180 tablets to be taken three every day (vitamin $\mathrm{D}_{3} 10 \mu \mathrm{g}$ and calcium $400 \mathrm{mg}$ per tablet). The second, third, and fourth visit was carried out as the first visit, with the addition of compliance estimation by count of remaining tablets.

\section{Outcome measures}

The primary outcome measure was the between-group differences in day and night values from the $24 \mathrm{hr}-\mathrm{AMBP}$ recording systolic and diastolic BP. The secondary outcome was the between-group comparisons of angiotensinogen, renin activity, angiotensin I, angiotensin II, aldosterone, epinephrine, and norepinephrine.

\section{Measurements}

\section{Lifestyle}

Through a questionnaire, the participants habit of exercise, smoking and alcohol consumption status was obtained. Smoking: "How many cigarettes have you smoked in the last seven days?" grouped into smoking yes/no. Alcohol: "How many units (12 g) of alcohol have you beendrinking in the last seven days?" grouped into alcohol yes/no. Exercise habits: "How many hours have you spent on 
exercise in the last seven days?" grouped into three groups; "0-2", " $2-7$ ", and "7 or more".

Medical history was obtained through a personal interview to ensure that the subjects were clinically healthy and did not fulfil any of the exclusion criteria. Height was measured using a vertical mounted $\mathrm{cm}$ ruler. Weight was measured using an electronic weight (OBH Nordic 6295). Calculation of compliance as the difference in prescribed intake and actual intake divided by prescribed intake of vitamin D supplementation.

\section{Blood pressure measurement}

Twentyfour hour ambulatory blood pressure data was recorded with the SpaceLabs 90207 oscillometric unit (Spacelabs, Redmond CA). The default daytime interval was set from 07.00 to $23.00 \mathrm{hr}$ and night time interval was set from 23.00 to $07.00 \mathrm{hr}$. If participants reported other sleep habits, default values were not used, instead the actual day and night time were used. In the day time BP was measured for every $20 \mathrm{~min}$ and every $30 \mathrm{~min}$ at night time to fullfil the European guidelines for AMBP measuring at least 14-day time and seven-night time measurements.

\section{Biochemical Analyses}

\section{Sympathetic nervous system activity}

Sympathetic nervous system activity (SNS) was assessed by measurement of plasma epinephrine and norepinephrine after 30 min. at rest in supine position. Blood samples were obtained in prechilled EDTA-tubes and centrifuged at $5{ }^{\circ} \mathrm{C}$ for $10 \mathrm{~min}$. at 3, $000 \mathrm{rpm}$ and afterwards stored at -80 until analyzed. Plasma norepinephrine and epinephrine was analysed with a commercial RIA-kit (2-Cat RIA from Labor Diagnostika Nord, Nordhon Germany). Catecholamine was calculated as the sum of epinephrine and norepinephrine.

\section{Renin-angiotensin-aldosterone system}

Renin-angiotensin-aldosterone system activity was assessed after $30 \mathrm{~min}$ of rest in supine position applying both in-house and commercial available biochemical methods. Blood samples for angiotensinogen were obtained in lithium heparin tubes and measured with the antibody trapping method. Blood sample for renin was obtained in pre-chilled EDTA tubes and measured with RIA based on renin activity. Blood samples $10 \mathrm{~mL}$ each for angiotensin I+II was obtained in tubes prepared with inhibitor and measured with an in-house RIA-based method. Blood samples for aldosterone were obtained in tubes with a serum clot activator and analysed with Siemens RIA Coat-a-count.

\section{Serum-25-Hydroxyvitamin D}

Serum-25[OH]D was analyzed with the chemiluminescent immunoassay (Liaison ${ }^{\circledR} 25-\mathrm{OH}$ Vitamin D Total Assay; Diasorin Inc., Saluggia (Vercelli), Italy).

\section{Statistical Analyses}

Sample size calculation for the primary outcome was based on the least relevant effect size of $6 \mathrm{mmHg}$ with an $\mathrm{SD}=5 \mathrm{mmHg}, \alpha=0.05$, and $\beta=0.80$, we calculated a sample size of 15 subjects for each group to be enrolled.

The continuous data was reported as means and Standard Deviations (SD) when data followed a normal distribution or medians and Interquartile Range (IQR) when they did not. Visual inspection of the continuous data was used to determinate the distribution. For categorical data, percentages were used.

Skewed variables were $\log (\mathrm{e})$ transformed before use in parametric statistical analysis.

Group analysis at baseline was performed with student's t-test or $\chi^{2}$-test. The main analysis of the outcome was by originally assigned groups. We attempted to follow-up on subjects who withdraw by phone, texting, and e-mail. Missing data was assumed missing at random.

A mixed model was applied to take advantage of repeated measurements and deal with missing data. Comparison of simple effects was performed at each visit without separating data in one analysis, to test for the effect of supplementation on visits. For all statistics, (SAS ${ }^{\oplus}$ Version 9.3, Cary, NC, USA) was used. We considered a p-value of $<0.05$ statistical significant.

\section{Results}

Two participants with vitamin D insufficiency and one vitamin D sufficient were excluded on the basis of S-25[OH]D, as they were no longer within the inclusion criteria. Two men and one woman in the control group and two men and one woman in the insufficient group did not complete all four visits, Table 1.

The first baseline visit was performed in October 2012 and the last follow-up visit was performed in August 2014. The analysis comprised in total 11 males aged $20.4 \pm 1.7 \mathrm{yrs}$ and 16 females aged $21.0 \pm 2.2 \mathrm{yrs}$. The baseline characteristics of the participants are given in Table 1 . At baseline, no significant differences were found regarding age, height, weight, systolic BP, sex, tobacco, and alcohol consumption between the two groups. At baseline, the group with insufficient vitamin D had higher diastolic BP compared to controls.

The period of supplementation (median [Interquartile Range (IQR)]) for vitamin D was 184 [180-200] days for the insufficiency group and 183 [179-200] days for the control group.

The effect of vitamin D supplementation on S-25[OH]D is shown in Figure 1A. Serum-25[OH]D in the insufficiency group increased from 32.0 (IQR 16.5) nmol/L at visit one to 64.5 (IQR 8.6) nmol/L at visit four. In the control group the change was from 99.9 (IQR 24.1) $\mathrm{nmol} / \mathrm{L}$ at first visit to 96.1 (IQR 27.1) $\mathrm{nmol} / \mathrm{L}$ at visit four. The estimated treatment effect of vitamin D supplementation on S-25[OH] $\mathrm{D}(95 \% \mathrm{Cl})$ was an impressive mean increase of 38.1 (Range 25.1 to $51.1) \mathrm{nmol} / \mathrm{L}$ for the insufficiency group compared to the controls $(\mathrm{p}<0.0001)$.

The effect of vitamin D supplementation on systolicBP (24 hr-AMBP, daytime) is shown in Figure 1C. Systolic BP (24 hr-AMBP, daytime) in the insufficiency group decreased from 124.5 (IQR 12.3) $\mathrm{mmHg}$ at visit one to 120.4 (IQR 9.5) 
$\mathrm{mmHg}$ at visit four. In the control group systolic-BP (24 hr-AMBP, daytime) remained unchanged from 115.8 (IQR 8.2) $\mathrm{mmHg}$ at first visit to 115.6 (IQR 7.3) $\mathrm{mmHg}$ at visit four. The estimated treatment effect of vitamin D supplementation on systolic-BP (24 hr-AMBP, daytime) was a significant decrease of -6.6 (IQR 2.4) $\mathrm{mmHg}$, ( $\mathrm{p}=$ 0.009 ) for the insufficiency group compared to the control group.

The effect of vitamin D supplementation on diastolic-BP (24 hrAMBP, daytime) is shown in Figure 1D. Diastolic-BP (24hr-AMBP, daytime) in the insufficiency group decreased from 73.1 (IQR 10.9) $\mathrm{mmHg}$ at visit one to 71.1 (IQR 9.3) $\mathrm{mmHg}$ at visit four. In the control group diastolic-BP (24 hr-AMBP, daytime) remained unchanged from 68.1 (IQR 5.4) $\mathrm{mmHg}$ at first visit to 69.3 (IQR 4.5) $\mathrm{mmHg}$ at visit four. The estimated treatment effect of vitamin $\mathrm{D}$ supplementation on diastolic-BP (24hr-AMBP, daytime) was a significant decrease of -4.5 (IQR 2.1) $\mathrm{mmHg},(\mathrm{p}=0.03)$ for the insufficiency group compared to the control group.

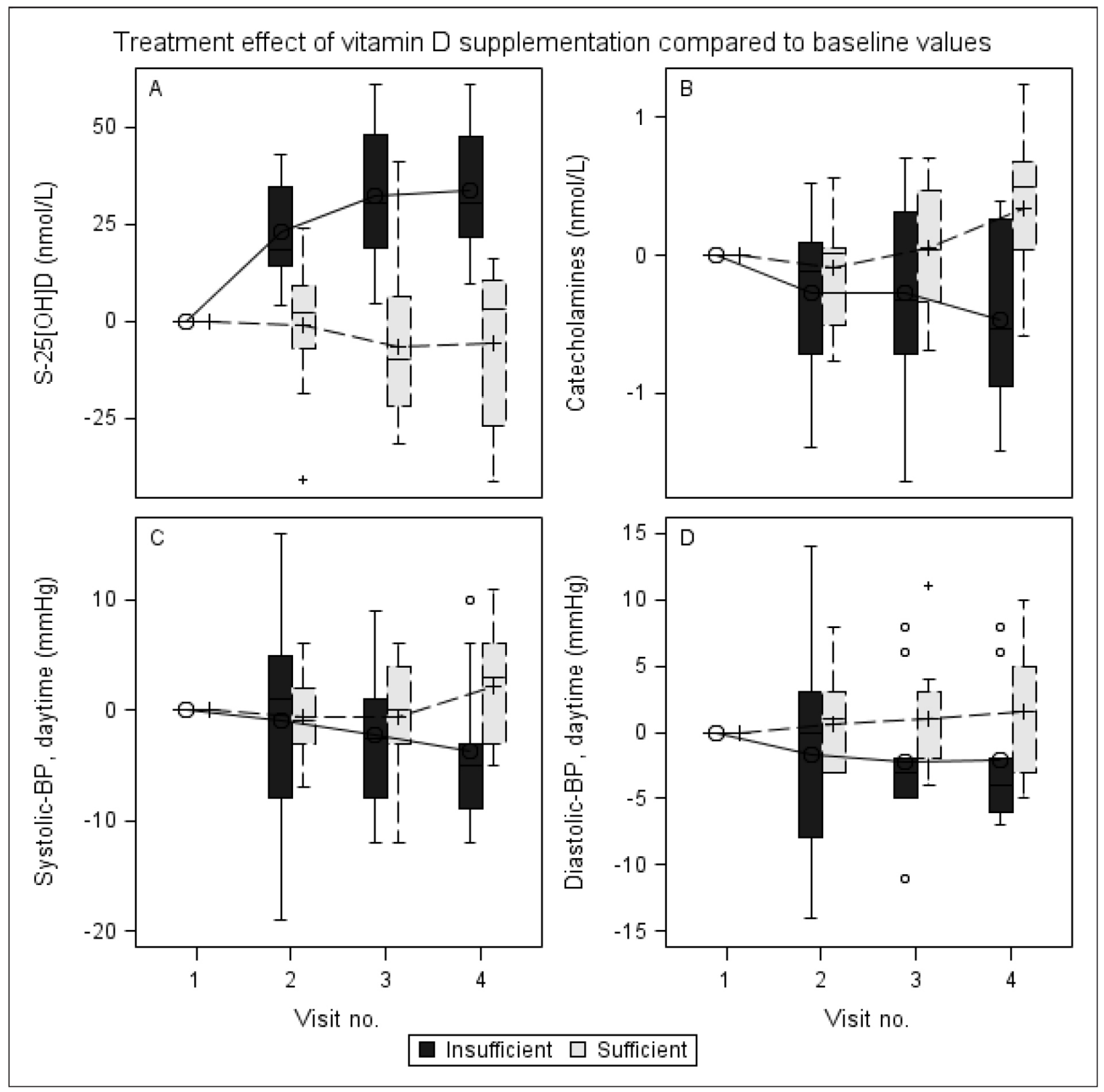

Figure 1. Treatment effect of Vitamin D supplementation compared to baseline values

Overall treatment effect over four visits of vitamin D supplementation (ergocholecalcipherol $30 \mu \mathrm{g} /$ day) in healthy young adults. All BPs are 24hr-AMBP. (A) Treatment effect on S-25[OH]-vitamin D $(\mathrm{nmol} / \mathrm{L})$ is significant at visit two $(\mathrm{p}=0.0001)$, three $(\mathrm{p}<.0001)$ and four $(\mathrm{p}<.0001)$; (B) Treatment effect on catecholamines $(\mathrm{nmol} / \mathrm{L})$ is significant at visit four ( $\mathrm{p}=0.0009)$; (C) Treatment effect on systolic-BP (mmHg) in daytime (0700-2300 hour) is significant at visit four ( $\mathrm{p}=0.009)$; (D) Treatment effect on diastolic-BP $(\mathrm{mmHg})$ in daytime $(0700-2300$ hour $)$ is significant at visit four $(\mathrm{p}=0.03)$. 
Table 1. Baseline characteristics of participants

\begin{tabular}{|c|c|c|c|}
\hline Variable & Sufficiency $(N=14)$ & $\begin{array}{l}\text { Insufficiency }(\mathrm{N} \\
=13)\end{array}$ & P-Value \\
\hline $\begin{array}{l}\text { Age (years) (Mean } \\
\pm \mathrm{SD})\end{array}$ & $20.5 \pm 2.4$ & $21.7 \pm 2.0$ & $0.13^{1}$ \\
\hline $\begin{array}{l}\mathrm{S}-25[\mathrm{OH}] \mathrm{D}(\mathrm{nmol} / \mathrm{L}) \\
\text { (Median (Range) }\end{array}$ & $96.3(65.3-164.0)$ & $33.3(10.0-65.8)$ & \\
\hline $\begin{array}{l}\text { Weight }(\mathrm{kg}) \text { (Mean } \\
\pm \mathrm{SD})\end{array}$ & $70.1 \pm 11.1$ & $78.4 \pm 15.4$ & $0.23^{1}$ \\
\hline $\begin{array}{l}\text { Height }(\mathrm{cm})(\text { Mean } \\
\pm \mathrm{SD})\end{array}$ & $176.4 \pm 9.7$ & $174.2 \pm 6.0$ & $0.56^{1}$ \\
\hline $\begin{array}{l}\text { Office BP systolic } \\
(\mathrm{mmHg})(\text { Mean } \pm \mathrm{SD})\end{array}$ & $120.6 \pm 8.6$ & $126.6 \pm 10.8$ & $0.12^{1}$ \\
\hline $\begin{array}{l}\text { Office BP diastolic } \\
(\mathrm{mmHg})(\text { Mean } \pm \mathrm{SD})\end{array}$ & $69.1 \pm 5.1$ & $79.0 \pm 14.7$ & $0.039^{1}$ \\
\hline \multicolumn{4}{|l|}{ Sex } \\
\hline Women & $10(62.5 \%)$ & $6(37.5 \%)$ & $0.18^{2}$ \\
\hline Men & $4(36.4 \%)$ & $7(63.6 \%)$ & \\
\hline \multicolumn{4}{|l|}{ Tobacco } \\
\hline No & $13(56.5 \%)$ & $10(43.5 \%)$ & $0.24^{2}$ \\
\hline Yes & $1(25.0 \%)$ & $3(75.0 \%)$ & \\
\hline \multicolumn{4}{|l|}{ Alcohol consumption } \\
\hline No & $8(57.1 \%)$ & $6(42.9 \%)$ & $0.57^{2}$ \\
\hline Yes & $6(46.2 \%)$ & $7(53.8 \%)$ & \\
\hline \multicolumn{4}{|l|}{$\begin{array}{l}\text { Physical Activity } \\
\text { (hours/week) }\end{array}$} \\
\hline $0-2$ & $1(11.1 \%)$ & $8(88.9 \%)$ & $0.011^{2}$ \\
\hline $2-7$ & $5(71.4 \%)$ & $2(28.6 \%)$ & \\
\hline 7 or more & $8(72.7 \%)$ & $3(27.3 \%)$ & \\
\hline
\end{tabular}

Baseline characteristics of the youngsters with sufficient levels of S-25[OH]-vitamin D (controls) and with insufficient levels of S-25[OH]-vitamin D

The effect of vitamin D supplementation on systolic-BP (24 hrAMBP, nighttime) is given in Table 2. Systolic-BP (24 hr-AMBP, night time) in the insufficiency group decreased from 106.8 (IQR 11.2) $\mathrm{mmHg}$ at visit one to 103.2 (IQR 12.7) $\mathrm{mmHg}$ at visit four. Within the control group systolic-BP (24 hr-AMBP, night time) decreased from 105.3 (IQR 7.1) $\mathrm{mmHg}$ at first visit to 102.8 (IQR 6.7) $\mathrm{mmHg}$ at visit four. The estimated treatment effect of vitamin $\mathrm{D}$ supplementation on systolic-BP (24 hr-AMBP, nighttime) was an insignificant increase of in average 0.7 (IQR 3.4) $\mathrm{mmHg}$, $(\mathrm{p}=0.8)$ for the insufficiency group compared to the controls.

The effect of vitamin D supplementation on diastolic-BP (24 hr-AMBP, nighttime) is presented in Table 2. Diastolic-BP (24 hrAMBP, night time) in the insufficiency group remained unchanged from 55.3 (IQR 7.1) $\mathrm{mmHg}$ at visit one to 54.7 (IQR 10.8) $\mathrm{mmHg}$ at visit four. In the control group diastolic-BP (24 hr-AMBP, night time) remained unchanged from 56.8 (IQR 6.2) $\mathrm{mmHg}$ at the first visit to 57.5 (IQR 3.9) $\mathrm{mmHg}$ at visit four. The estimated treatment effect of vitamin D supplementation on diastolic-BP (24hr-AMBP, night time) shows a decreasing trend of $-1.3($ IQR 2.8$) \mathrm{mmHg},(\mathrm{p}=0.6)$ for the insufficiency group compared to the controls.

For the secondary outcome, we observed an effect of vitamin D supplementation from visitoneto visitfour on catecholamines. The effect of vitamin D supplementation on catecholamine is shown in Figure 1B. Catecholamines in the insufficiency group decreased from 1.79 (IQR 0.49 ) $\mathrm{nmol} / \mathrm{L}$ at visit one to 1.26 (IQR 0.37) $\mathrm{nmol} / \mathrm{L}$ at visit four, estimated treatment effect in the group was a significant decrease of $-0.47(\mathrm{IQR} 0.20) \mathrm{nmol} / \mathrm{L},(\mathrm{p}=0.02)$. Catecholamines in the control group showed a trend of increased from 1.04 (IQR 0.26) nmol/L at visit one to 1.40 (IQR 0.51$) \mathrm{nmol} / \mathrm{L}$ at visit four, estimated change in the group was $0.33(\mathrm{IQR} 0.21) \mathrm{nmol} / \mathrm{L},(\mathrm{p}=0.11)$. The estimated effect of vitamin $\mathrm{D}$ supplementation on catecholamines was a significant decrease of -0.77 (IQR 0.22 ) nmol/L for the insufficiency group compared to the controls $(\mathrm{p}=0.0009)$.

Norepinephrine in the insufficiency group decreased from 1.61 (IQR 0.48) $\mathrm{nmol} / \mathrm{L}$ at visit one to 1.19 (IQR 0.37) $\mathrm{nmol} / \mathrm{L}$ at visit four, estimated effect in the group was a significant decrease in norepinephrine of $-0.46(I Q R ~ 0.19) \mathrm{nmol} / \mathrm{L},(\mathrm{p}=0.02)$. Norepiniphrine in the control group increased from 0.94 (IQR 0.25$) \mathrm{nmol} / \mathrm{L}$ at first visit to 1.40 (IQR 0.51$) \mathrm{nmol} / \mathrm{L}$ at visit four, estimated effect was an insignificant decrease of 0.36 (IQR 0.19$) \mathrm{nmol} / \mathrm{L},(\mathrm{p}=0.06)$. The estimated effect of vitamin $\mathrm{D}$ supplementation on norepinephrine was a significant decrease of -0.80 (IQR 0.21$) \mathrm{nmol} / \mathrm{L}$, for the insufficiency group compared to the controls $(\mathrm{p}=0.0002)$.

Vitamin D supplementation showed no effect within groups nor overall for angiotensinogen, renin activity, angiotensin I, angiotensin II, aldosterone or epinephrine. No adverse events were recorded through the study.

\section{Discussion}

This randomised, controlled trial with vitamin D supplementation in normotensive youngsters over a period of 6 months included 15 controls with sufficient levels of vitamin D and 15 cases with insufficient levels of vitamin D. We observed a significant decrease of both systolic and diastolic blood pressure in the group with insufficient vitamin D levels. Vitamin D supplementation also lowered catecholamines, more specifically a significant decrease in norepinephrine. Conversely, we did not detect any change of the parameters in the RAAS. This points to vitamin D affecting BP through the SNS and not RAAS, contrasting other randomized controlled trials which found lower levels of renin and aldosterone [23, 42, 43].

Most studies investigating vitamin $\mathrm{D}$ supplementation on $\mathrm{BP}$ show a lack of effect. Looking at meta-analyses with pooled data from 64 randomized controlled trials show that only 8 report of beneficial effects with most studies having been conducted on normotensive participants and a duration of under a year [29, 44-51]. Two large scale trials with vitamin D supplements and a follow-up times of 3 and 7 years show no change in blood pressure $[52,53]$. These limitations also apply to our study which investigate normotensive participants 
over 6 months. Lasting effects beyond the 6 months are unknown, but it is worth noting that during daytime the treatment effect between the control and case groups increased at all visits, indicating that an even greater effect could potentially be seen at further time points.

Table 2. Effect of vitamin D supplementation on blood pressure and S-25[OH]-vitamin D

\begin{tabular}{|c|c|c|c|c|c|}
\hline & & \multicolumn{4}{|c|}{ Visit no. } \\
\hline & & 1. (Baseline) & 2. (30 days) & 3. (90 days) & 4. (180 days) \\
\hline \multirow{3}{*}{$\mathrm{S}-25[\mathrm{OH}] \mathrm{D}(\mathrm{nmol} / \mathrm{L})$} & Control & $99.9(24.1)$ & $97.8(27.6)$ & $94.4(33.2)$ & $96.1(27.1)$ \\
\hline & Insufficient & $32.0(16.5)$ & $54.1(15.0)$ & $63.2(16.6)$ & $64.5(8.6)$ \\
\hline & Treatment effect & . & $+23.6(5.9)$ & $+37.8(6.1)$ & $+38.1(6.5)$ \\
\hline \multirow{3}{*}{ Systolic BP, daytime (mmHg) } & Control & $115.8(8.2)$ & $115.5(10.1)$ & $114.2(9.7)$ & $115.6(7.3)$ \\
\hline & Insufficient & $124.5(12.3)$ & $122.2(9.3)$ & $120.3(9.3)$ & $120.4(9.5)$ \\
\hline & Treatment effect & . & $-1.2(2.3)$ & $-2.9(2.3)$ & $-6.6(2.4)$ \\
\hline \multirow{3}{*}{ Diastolic-BP daytime (mmHg) } & Control & $68.1(5.4)$ & $68.2(6.7)$ & $69.3(4.4)$ & $69.3(4.5)$ \\
\hline & Insufficient & $73.1(10.9)$ & $70.5(8.0)$ & $69.2(9.5)$ & $71.1(9.3)$ \\
\hline & Treatment effect & . & $-2.8(1.9)$ & $-3.9(2.0)$ & $-4.5(2.1)$ \\
\hline \multirow{3}{*}{$\begin{array}{l}\text { Systolic-BP nighttime } \\
(\mathrm{mmHg})\end{array}$} & Control & $105.3(7.1)$ & $105.5(10.2)$ & $102.0(8.4)$ & $102.8(6.7)$ \\
\hline & Insufficient & $106.8(11.2)$ & $107.8(11.4)$ & $103.1(10.6)$ & $103.2(12.7)$ \\
\hline & Treatment effect & . & $+3.3(3.1)$ & $+2.7(3.3)$ & $-0.7(3.4)$ \\
\hline \multirow{3}{*}{$\begin{array}{l}\text { Diastolic-BP nighttime } \\
(\mathrm{mmHg})\end{array}$} & Control & $56.8(6.2)$ & $57.3(4.5)$ & $56.2(4.8)$ & $57.5(3.9)$ \\
\hline & Insufficient & $55.3(7.1)$ & $56.8(10.8)$ & $51.1(11.0)$ & $54.7(10.8)$ \\
\hline & Treatment effect & . & $+2.9(2.5)$ & $-1.3(2.7)$ & $-1.3(2.8)$ \\
\hline
\end{tabular}

Controls have normal S-25[OH]-vitamin D at baseline whereas all vitamin D insufficient participants had S-25[OH]-vitamin D below $50 \mathrm{nmol} / \mathrm{L}$ at baseline. All BP are 24hr-AMBP. Estimated treatment effect (individual change from baseline compared to groups). Statistically significant $(\mathrm{p}<0.05)$ treatment effects are marked with bold. Data presented as median (Interquatile Range)

Vitamin D insufficiency in itself did not activate the RAAS system in our population as the baseline values for the RAAS did not differ between the groups. Rejnmark et al [54] demonstrated in postmenopausal women, that only the concentrations of S-25[OH] D below $80 \mathrm{nmol} / \mathrm{L}$ increased $1,-25(\mathrm{OH})_{2} \mathrm{D}_{3}$ and that Parathyroid Hormone $(\mathrm{PTH})$ are better related to $1,-25(\mathrm{OH})_{2} \mathrm{D}_{3}$ than $25[\mathrm{OH}]$ D. A similar effect could well be in play here too, as the $25[\mathrm{OH}]$ $\mathrm{D}$ concentration in our subjects was not low enough to alter 1 , $-25(\mathrm{OH})_{2} \mathrm{D}_{3}$ and stimulate the RAAS-system. The lack of changes in the RAAS system under vitamin D supplementation is a strong argument for the RAAS system not to be modulated by S-25[OH]D in healthy young adults. However, the unchanged RAAS system does not exclude an impact of vitamin D insufficiency on the RAAS activation in already hypertensive and elderly patients.

As expected vitamin D supplementation increased the concentration of S-25[OH]D in the insufficient group whereas the control group remained at a steady state level as intended. This study design handled the seasonal variation well as none from the control group decreased significantly.
Besides the short observation period the study has few limitations. The two groups investigated differed only in physical activity at baseline; the control group had a higher mean physical activity, compared to the insufficient group. This might affect BP and explain the initial difference in total plasma catecholamines. The change over time in total catecholamines is only attributable to changes in $\mathrm{S}-25[\mathrm{OH}] \mathrm{D}$ as this was the only parameter that differed between the two groups between visits. Catecholamines in plasma are a useful measure of the activity of the SNS, despite known limitations. It acts as a systemic index, thus providing no pattern of regional activity of the SNS, i.e. in the heart or in the BP modifying arteries. Another factor to consider, is whether calcium supplementation plays a role in itself. Meta analyses have shown a small effect on BP, especially in patients with insufficient dietary intake [55]. Both groups received calcium supplements, but we cannot rule out the possibility that the patients with insuffient vitamin D could have a greater benefit than the controls.

In conclusion, increase in S-25[OH]D by supplementation might have a clinical relevant effect on lowering the blood pressure in 
Peter Schwarz (2019) Blood Pressure in Healthy Youngsters is modified by Vitamin-D Supplementation

healthy young adults, and might be associated with a modulation of the activity of the SNS but not RAAS. The increase of S-25[OH]D by vitamin D supplementation decreases catecholamines at rest. Further investigations of S-25[OH]D modulation of the SNS is needed to elucidate the importance of S-25[OH]D on BP regulation.

Table 3. Effect of vitamin D supplementation on the Renin-Angiotensin-Aldosterone-System

\begin{tabular}{|c|c|c|c|c|c|}
\hline & & \multicolumn{4}{|c|}{ Visit no. } \\
\hline & & 1. (Baseline) & 2. (30 days) & 3. (90 days) & 4. (180 days) \\
\hline \multirow[t]{3}{*}{$\mathrm{S}-25[\mathrm{OH}] \mathrm{D}(\mathrm{nmol} / \mathrm{L})$} & Control & $99.9(24.1)$ & $97.8(27.6)$ & $94.4(33.2)$ & $96.1(27.1)$ \\
\hline & Insufficient & $32.0(16.5)$ & $54.1(15.0)$ & $63.2(16.6)$ & $64.5(8.6)$ \\
\hline & Treatment effect & . & $+23.6(5.9)$ & $+37.8(6.1)$ & $+38.1(6.5)$ \\
\hline \multirow[t]{3}{*}{ Angiotensinogen $(\mathrm{nmol} / \mathrm{L})$} & Control & $1986(1361)$ & 1953 (1286) & $2552(1829.0)$ & $2471(1436)$ \\
\hline & Insufficient & $1561(1044)$ & $1498(727)$ & 1807 (1466) & $2116(1713)$ \\
\hline & Treatment effect & . & $+137(290)$ & +403 (296) & $+223(330)$ \\
\hline \multirow[t]{3}{*}{ Renin (mIU/L) } & Control & $15.5(11.4)$ & $42.4(69.0)$ & $20.6(26.3)$ & $17.0(12.9)$ \\
\hline & Insufficient & $33.7(31.2)$ & $34.7(33.1)$ & $34.6(19.5)$ & $24.7(20.0)$ \\
\hline & Treatment effect & . & $+24.1(12.0)$ & $+3.1(12.3)$ & $+13.6(13.9)$ \\
\hline \multirow[t]{3}{*}{ Angiotensin I (pmol/L) } & Control & $40.5(24.9)$ & $36.0(35.1)$ & $50.6(49.3)$ & $30.2(14.7)$ \\
\hline & Insufficient & $45.8(34.1)$ & $36.2(22.5)$ & $68.8(50.2)$ & $44.4(29.5)$ \\
\hline & Treatment effect & . & $+1.9(14.2)$ & $-14.9(14.2)$ & $-6.5(15.3)$ \\
\hline \multirow[t]{3}{*}{ Angiotensin II (pmol/L) } & Control & $14.2(12.9)$ & $12.6(9.7)$ & $17.1(13.0)$ & $14.0(10.1)$ \\
\hline & Insufficient & $17.9(15.9)$ & $17.1(12.0)$ & $21.7(12.6)$ & $17.3(14.6)$ \\
\hline & Treatment effect & . & $+0.2(5.8)$ & $-2.5(5.9)$ & $+0.9(6.4)$ \\
\hline \multirow[t]{3}{*}{ Aldosterone (pmol/L) } & Control & $244(152)$ & $211(145)$ & $448(466)$ & $318(234)$ \\
\hline & Insufficient & $197(82)$ & $302(189)$ & $291(169)$ & $224(138)$ \\
\hline & Treatment effect & . & $-136.7(99.6)$ & +105.7 (101.9) & $+36.9(109.5)$ \\
\hline \multirow[t]{3}{*}{ Norepinephrine (nmol/L) } & Control & $0.94(0.25)$ & $0.79(0.39)$ & $0.95(0.32)$ & $1.33(0.50)$ \\
\hline & Insufficient & $1.61(0.48)$ & $1.31(0.61)$ & $1.34(0.61)$ & $1.19(0.37)$ \\
\hline & Treatment effect & . & $+0.15(0.18)$ & $+0.29(0.19)$ & $+0.80(0.21)$ \\
\hline \multirow[t]{3}{*}{ Epinephrine (nmol/L) } & Control & $0.08(0.04)$ & $0.08(0.07)$ & $0.08(0.06)$ & $0.07(0.07)$ \\
\hline & Insufficient & $0.08(0.03)$ & $0.10(0.08)$ & $0.08(0.04)$ & $0.08(0.04)$ \\
\hline & Treatment effect & . & $-0.01(0.02)$ & $-0.01(0.02)$ & $-0.01(0.02)$ \\
\hline
\end{tabular}

Estimated treatment effect (individual change from baseline compared to groups). Statistically significant ( $<0.05$ ) treatment effects are marked with bold. Data presented as median (Interquartile Range)

\section{References}

1. Ramagopalan SV, Heger A, Berlanga AJ, Maugeri NJ, Lincoln MR, et al. (2010) A ChIP-seq defined genome-wide map of vitamin D receptor binding: associations with disease and evolution. Genome research 20: 1352-1360.

2. Hossein-nezhad A, Holick MF (2013) Vitamin D for health: a global perspective. Mayo Clin Proc 88: 720-755. [crossref]

3. Autier P, Boniol M, Pizot C, Mullie P (2014) Vitamin D status and ill health: a systematic review. Lancet Diabetes Endocrinol 2: 76-89. [crossref]

4. Bjelakovic G, Gluud LL, Nikolova D, Whitfield K, Wetterslev J, et al. (2011) Vitamin D supplementation for prevention of mortality in adults. Cochrane Database Syst Rev 6: CD007470.

5. Wang L, Song Y, Manson JE, Pilz S, Marz W, et al. (2012) Circulating 25-hydroxyvitamin $\mathrm{D}$ and risk of cardiovascular disease: a meta-analysis of prospective studies. CircCardiovascQualOutcomes. 5: 819-829.
6. Leu M, Giovannucci E (2011) Vitamin D: epidemiology of cardiovascular risks and events. Best Pract Res Clin Endocrinol Metab 25: 633-646. [crossref]

7. McKenna MJ (1992) Differences in vitamin D status between countries in young adults and the elderly. Am J Med 93: 69-77. [crossref]

8. Powe CE, Evans MK, Wenger J, Zonderman AB, Berg AH, et al. (2013) Vitamin D-binding protein and vitamin D status of black Americans and white Americans. $N$ Engl J Med 369: 1991-2000. [crossref]

9. Holick MF, Chen TC (2008) Vitamin D deficiency: a worldwide problem with health consequences. Am J Clin Nutr 87: 1080S-1086S. [crossref]

10. Webb AR, Kline L, Holick MF (1988) Influence of season and latitude on the cutaneous synthesis of vitamin D3: exposure to winter sunlight in Boston and Edmonton will not promote vitamin D3 synthesis in human skin. J Clin Endocrinol Metab 67: 373-378.

11. Rahimi K, Emdin CA, MacMahon S (2015) The epidemiology of blood pressure and its worldwide management. Circ Res 116: 925-936. [crossref] 
12. Kearney PM, Whelton M, Reynolds K, Muntner P, Whelton PK, et al. (2005) Global burden of hypertension: analysis of worldwide data. Lancet 365: 217-223. [crossref]

13. Heidenreich PA, Trogdon JG, Khavjou OA, Butler J, Dracup K, et al. (2011) Forecasting the future of cardiovascular disease in the United States: a policy statement from the American Heart Association. Circulation123: 933-944. [crossref]

14. Jones G (2008) Pharmacokinetics of vitamin D toxicity. Am J Clin Nutr 88: 582S-586S. [crossref]

15. Hathcock JN, Shao A, Vieth R, Heaney R (2007) Risk assessment for vitamin D. Am J Clin Nutr 85: 6-18. [crossref]

16. Gepner AD, Ramamurthy R, Krueger DC, Korcarz CE, Binkley N, et al. (2012) A prospective randomized controlled trial of the effects of vitamin $\mathrm{D}$ supplementation on cardiovascular disease risk. PLoSOne 7: 36617.

17. Witham MD, Price RJ, Struthers AD, Donnan PT, Messow CM, et al. (2013) Cholecalciferol treatment to reduce blood pressure in older patients with isolated systolic hypertension: the VitDISH randomized controlled trial. JAMA Intern Med 173: 1672-1679. [crossref]

18. Larsen T, Mose FH, Bech JN, Hansen AB, Pedersen EB (2012) Effect of cholecalciferol supplementation during winter months in patients with hypertension: a randomized, placebo-controlled trial. Am J Hypertens 25: 1215-1222.

19. Jehle S, Lardi A, Felix B, Hulter HN, Stettler C, et al. (2014) Effect of large doses of parenteral vitamin D on glycaemic control and calcium/phosphate metabolism in patients with stable type 2 diabetes mellitus: a randomised, placebo-controlled, prospective pilot study. Swiss Med Wkly 144: 13942. [crossref]

20. Witham MD, Adams F, Kabir G, Kennedy G, Belch JJ, et al. (2013) Effect of short-term vitamin D supplementation on markers of vascular health in South Asian women living in the UK--a randomised controlled trial. Atherosclerosis 230: 293-299. [crossref]

21. Forman JP1, Scott JB, Ng K, Drake BF, Suarez EG, et al. (2013) Effect of vitamin D supplementation on blood pressure in blacks. Hypertension 61: 779-785. [crossref]

22. Kampmann U, Mosekilde L, Juhl C, Moller N, Christensen B, Rejnmark L, et al. (2014) Effects of 12 weeks high dose vitamin D3 treatment on insulin sensitivity, beta cell function, and metabolic markers in patients with type 2 diabetes and vitamin D insufficiency - a double-blind, randomized, placebo-controlled trial. Metabolism 63: 1115-1124

23. Pfeifer M, Begerow B, Minne HW, Nachtigall D, Hansen C (2001) Effects of a short-term vitamin $\mathrm{D}(3)$ and calcium supplementation on blood pressure and parathyroid hormone levels in elderly women. J Clin Endocrinol Metab 86: 16331637. [crossref]

24. Dalbeni A, Scaturro G, Degan M, Minuz P, Delva P (2014) Effects of six months of vitamin D supplementation in patients with heart failure: a randomized doubleblind controlled trial. Nutr Metab CardiovascDis 24: 861-868.

25. Wamberg L, Kampmann U, Stodkilde-Jorgensen H, Rejnmark L, Pedersen SB, et al. (2013) Effects of vitamin D supplementation on body fat accumulation, inflammation, and metabolic risk factors in obese adults with low vitamin D levels - results from a randomized trial. Eur J Intern Med 24: 644-649.

26. Scragg R, Slow S, Stewart AW, Jennings LC, Chambers ST, et al. (2014) Longterm high-dose vitamin D3 supplementation and blood pressure in healthy adults: a randomized controlled trial. Hypertension 64: 725-730. [crossref]

27. Sollid ST, Hutchinson MY, Fuskevåg OM, Figenschau Y, Joakimsen RM, et al. (2014) No effect of high-dose vitamin D supplementation on glycemic status or cardiovascular risk factors in subjects with prediabetes. Diabetes Care 37: 2123 2131. [crossref]

28. Jorde R, Sneve M, Torjesen P, Figenschau Y (2010) No improvement in cardiovascular risk factors in overweight and obese subjects after supplementation with vitamin D3 for 1 year. J Intern Med 267: 462-472. [crossref]

29. Kunutsor SK, Burgess S, Munroe PB, Khan H (2014) Vitamin D and high blood pressure: causal association or epiphenomenon? Eur J Epidemiol 29: 1-14. [crossref]

30. Schleithoff SS, Zittermann A, Tenderich G, Berthold HK, Stehle P, et al. (2006) Vitamin D supplementation improves cytokine profiles in patients with congestive heart failure: a double-blind, randomized, placebo-controlled trial. Am J Clin Nutr 83: 754-759. [crossref]

31. Arora P, Song Y, Dusek J, Plotnikoff G, Sabatine MS, et al. (2015) Vitamin D therapy in individuals with prehypertension or hypertension: the DAYLIGHT trial. Circulation 131: 254-262. [crossref]

32. Witham MD, Ireland S, Houston JG, Gandy SJ, Waugh S, et al. (2014) Vitamin D therapy to reduce blood pressure and left ventricular hypertrophy in resistant hypertension: randomized, controlled trial. Hypertension 63: 706-712.
33. Kienreich K, Grubler M, Tomaschitz A, Schmid J, Verheyen N, et al. (2013) Vitamin D, arterial hypertension \& cerebrovascular disease. Indian J Med Res 137; 669-679.

34. Wood AD1, Secombes KR, Thies F, Aucott L, Black AJ, et al. (2012) Vitamin D3 supplementation has no effect on conventional cardiovascular risk factors: a parallel-group, double-blind, placebo-controlled RCT. J Clin Endocrinol Metab 97: 3557-3568. [crossref]

35. Boron WF, Boulpaep EL (2003) Medical Physiology. 1 (edn). Philadelphia: Saunders; 2003 .

36. Mann MC, Exner DV, Hemmelgarn BR, Turin TC, Sola DY, et al. (2014) Vitamin D supplementation is associated with improved modulation of cardiac autonomic tone in healthy humans. International journal of cardiology 172: 506-508.

37. Schmid A, Walther B (2013) Natural vitamin D content in animal products. Adv Nutr 4: 453-462. [crossref]

38. Bogh MK, Schmedes AV, Philipsen PA, Thieden E, Wulf HC (2011) Vitamin $\mathrm{D}$ production depends on ultraviolet-B dose but not on dose rate: a randomized controlled trial. Exp Dermatol 20: 14-18. [crossref]

39. Li YC (2003) Vitamin D regulation of the renin-angiotensin system. $J$ Cell Biochem 88: 327-331. [crossref]

40. Baksi SN, Hughes MJ (1984) Alteration of adrenal catecholamine levels in the rat after dietary calcium and vitamin D deficiencies. Journal of the autonomic nervous system 11: 393-396.

41. Baksi SN (1988) Altered pressor response to norepinephrine in calcium- and vitamin D-deficient rats. Clin Exp Hypertens A 10: 811-832. [crossref]

42. Schroten NF, Ruifrok WP, Kleijn L, Dokter MM, Sillje HH, et al. (2013) Short-term vitamin D3 supplementation lowers plasma renin activity in patients with stable chronic heart failure: an open-label, blinded end point, randomized prospective trial (VitD-CHF trial). Am Heart $J$ 166: 357-364.

43. Grubler MR, Gaksch M, Kienreich K, Verheyen N, Schmid J, et al. (2016) Effects of Vitamin D Supplementation on Plasma Aldosterone and Renin-A Randomized Placebo-Controlled Trial. J Clin Hypertens (Greenwich) 18: 608-613.

44. Witham MD, Nadir MA, Struthers AD (2009) Effect of vitamin D on blood pressure: a systematic review and meta-analysis. J Hypertens 27: 1948-1954. [crossref]

45. Wu SH, Ho SC, Zhong L (2010) Effects of vitamin D supplementation on blood pressure. South Med J 103: 729-737. [crossref]

46. Lee KJ, Lee YJ (2016) Effects of vitamin D on blood pressure in patients with type 2 diabetes mellitus. Int $J$ Clin Pharmacol Ther 54: 233-242. [crossref]

47. Elamin MB, Abu Elnour NO, Elamin KB, Fatourechi MM, Alkatib AA, et al. (2011) Vitamin D and cardiovascular outcomes: a systematic review and meta-analysis. $J$ Clin Endocrinol Metab 96: 1931-1942. [crossref]

48. Pittas AG, Chung M, Trikalinos T, Mitri J, Brendel M, et al. (2010) Systematic review: Vitamin D and cardiometabolic outcomes. Ann Intern Med 152: 307-314. [crossref]

49. Beveridge LA, Struthers AD, Khan F, Jorde R, Scragg R, et al. (2015) Effect of Vitamin D Supplementation on Blood Pressure: A Systematic Review and Metaanalysis Incorporating Individual Patient Data. JAMA Intern Med 175: 745-754. [crossref]

50. Golzarand M, Shab-Bidar S, Koochakpoor G, Speakman J R, Djafarian K (2016) Effect of vitamin D3 supplementation on blood pressure in adults: An updated meta-analysis. Nutr Metab Cardiovasc Dis 26: 663-673. [crossref]

51. Manousopoulou A, Al-Daghri NM, Garbis SD (2015) Vitamin D and cardiovascular risk among adults with obesity: a systematic review and meta-analysis. Eur J Clin Invest 45: 1113-1126. [crossref]

52. Margolis KL1, Ray RM, Van Horn L, Manson JE, Allison MA, et al. (2008) Effect of calcium and vitamin D supplementation on blood pressure: the Women's Health Initiative Randomized Trial. Hypertension 52: 847-855. [crossref]

53. Scragg R, Stewart AW, Waayer D, Lawes CMM, Toop L, Sluyter J, et al. (2017) Effect of Monthly High-Dose Vitamin D Supplementation on Cardiovascular Disease in the Vitamin D Assessment Study: A Randomized Clinical Trial. JAMA Cardiol 2: 608-616.

54. Rejnmark L, Vestergaard P, Heickendorff L, Mosekilde L (2008) Plasma $1,25(\mathrm{OH}) 2 \mathrm{D}$ levels decrease in postmenopausal women with hypovitaminosis D. Eur J Endocrinol 158: 571-576. [crossref]

55. van Mierlo LA, Arends LR, Streppel MT, Zeegers MP, Kok FJ, et al. (2006) Blood pressure response to calcium supplementation: a meta-analysis of randomized controlled trials. J Hum Hypertens 20: 571-580.

\section{Citation:}

Rune Tønnesen, Kristian Buch, Peter Hambak Hovind, Lars Thorbjørn Jensen and Peter Schwarz (2019) Blood Pressure in Healthy Youngsters is modified by Vitamin-D Supplementation. Endocrinol Diabetes Metab J Volume 3(2): 1-8 